\title{
Opposite role of slow and fast GABAergic inhibition in synchronization and spike timing precision Noelia Montejo* and Dominique Martinez
}

\author{
Address: LORIA-Campus Scientifique, Bâtiment C-BP 239-54506 Vandoeuvre-lès-Nancy Cedex, France \\ Email: Noelia Montejo* - Noelia.Montejo-Cervera@loria.fr \\ * Corresponding author
}

from Sixteenth Annual Computational Neuroscience Meeting: CNS*2007

Toronto, Canada. 7-12 July 2007

Published: 6 July 2007

BMC Neuroscience 2007, 8(Suppl 2):P5 I doi: I0.1 I86/I47|-2202-8-S2-P5 I

(C) 2007 Montejo and Martinez; licensee BioMed Central Ltd.

\section{Background}

The firing rate of projection neurons in the insect antennal lobe (AL) increases in presence of picrotoxin (GABA-A antagonist) or CGP54626 (GABA-B antagonist), hence demonstrating the existence of both slow and fast GABAergic inhibition [1]. Fast GABA-A inhibition is known to play a key role in synchronization and spike timing precision. Field potential oscillations and neural synchronization are indeed disrupted when the fast GABAergic synapses are pharmacologically blocked. The role of slow GABA-B inhibition is, however, unclear. On the one hand, spike timing precision increases following in vitro injection of hyperpolarizing current pulses, and higher precision is obtained for pulses of longer duration (see Fig. 4 in [2]). Thus, in vitro experimental data suggest that slow inhibition may enhance spike timing precision and synchronization. On the other hand, in vivo experimental data just show the opposite as spike timing precision increases, instead of decreasing as expected, when the slow inhibition is pharmacologically blocked (see Fig. 4 in [1]). To understand this paradox, we have built a computational model of the insect AL.

\section{Methods}

Based on previous work [3], our AL model is a network of quadratic integrate-and-fire (theta) neurons coupled with slow (determined by GABA-B receptors) and fast (determined by GABA-A receptors) inhibitory synapses. In this study, we consider a probability of synaptic failure ( $\mathrm{p}=$ 0.5 ) and three patterns of connectivity: global (all-to-all connections), heterogeneous (random connections with
0.5 probability) and homogeneous (random connections but with the same number of synaptic inputs per cell).

\section{Results}

Tight synchronization and precise spike timing are obtained (i) when the connectivity is global or homogeneous and the neurons are coupled by fast and slow inhibition without synaptic failure, or (ii) when the neurons are connected by fast inhibition alone, irrespective of the pattern of connectivity and the presence or not of synaptic failure. Asynchronous state and imprecise spike timing are obtained with slow inhibition (i) when the connectivity is heterogeneous or (ii) when the connectivity is global or homogeneous and with synaptic failure.

\section{Conclusion}

Our results predict that loss of synchronization is attributable to variance in the number of received slow inhibitory synaptic events (whereas fast inhibition is robust to such variability). This variance comes from heterogeneous connectivity or from the presence of synaptic failure, both of them being likely to occur in vivo [1]. In contrast, in vitro injection of hyperpolarizing current pulses, as done in [2], does not present such a variability which explains the apparent contradiction between in vivo and in vitro experimental data.

\section{References}

I. Wilson El, Laurent G: Role of GABAergic in shaping odorevoked spatiotemporal patterns in the Drosophila Antennal lobe. J Neurosci 2005, 25(40):9069-9079. 
2. Schaefer AT, Angelo K, Spors H, Margrie TW: Neuronal oscillations enhance stimulus discrimination by ensuring action potential precision. PLOS Biol 2006, 4(6): 1010-1024.

3. Martinez $D$ : Oscillatory synchronization requires precise and balanced feedback inhibition in a model of the insect antennal lobe. Neural Comput 2005, 17:2548-2570.

Publish with Biomed Central and every scientist can read your work free of charge

"BioMed Central will be the most significant development for disseminating the results of biomedical research in our lifetime. " Sir Paul Nurse, Cancer Research UK

Your research papers will be:

- available free of charge to the entire biomedical community

- peer reviewed and published immediately upon acceptance

- cited in PubMed and archived on PubMed Central

- yours - you keep the copyright

Submit your manuscript here:

http://www.biomedcentral.com/info/publishing_adv.asp 